\title{
Listening as Religious Practice (Part One) - Exploring Quantitative Data from an Empirical Study of the Cultural Habits of Music Fans
}

\section{CLIVE MARSH \& VAUGHAN S. ROBERTS}

\section{Abstract}

This article explores and reflects upon the role that music-consumption may be playing in the flexible field of cultural expression, identity formation and meaning-making activity in the West, as overt commitment to organised religion continues to decline and prove fragile. Using quantitative data from a 2009-10 study of 231 music-users the authors locate and analyse the respondents' declarations about their listening practices in relation to their other socio-cultural habits and life-commitments. The article explores the genre and themes of music listened to, the means by which the music is accessed, the frequency of listening and the scale and nature of non-musical commitments. The significance of differences between male and female respondents' replies, and between those of self-identifying religious and non-religious respondents is also considered. The paper concludes that whilst listening habits differ only slightly between religious and non-religious respondents, there are differences in three significant respects: music-use with respect to political self-expression; the accessing of 'life-worlds'/ the narratives that people live by; the frequency and technological format of listening.

\section{Keywords}

Music, religion, fandom, listening, practice, identity 


\section{I: Locating Music Use within Contemporary Practice}

As increasing numbers of people in many Western societies no longer identify with or participate in traditional religious beliefs and activities, so sources and forms 'of meaning and value beyond traditional forms of institutional religion' (Lynch Public Media 244) have long since begun to attract greater scholarly attention (e.g. Lyden, Woodhead et al., Butler Bass 76-83). Linda Woodhead argues the dramatic change in religious practice over the past thirty years is so significant that it should be called a 'de-reformation of religion': 'For most people, religion has ceased to be a matter of belonging to a clerically led community, affirming unchanging dogma, participating in prescribed rituals, and holding conservative social attitudes. It's transformed into something else' (Mind). Commenting further, when reviewing the findings of the $f_{12} \mathrm{~m}$ AHRC/ESRC Religion and Society research programme, Woodhead remarked: 'We've got to stop talking as if religions are packages of unchanging conservative dogmas, rituals and values. They are for a few people but not for most. The majority are a bit religious and interested in exploring things for themselves. They want religion to give meaning to their lives. They don't want to give their lives to a religious system' (British religion).

Alongside the changes to religion itself, the challenge of making sense of the alternatives is clear. Martyn Percy observes: 'There can be no question that secularisation and consumer culture presents a profound problem for the churches. Malls compete with cathedrals for people, space and attention. Leisure and shopping compete with worship' is followed up with the recognition that 'especially individually-centred, therapeutically-attuned forms of spirituality' result (Percy 194). Some have argued that this change is particularly noticeable in Europe and less so in the rest of the world (Davie). However, data increasingly suggests that a similar 'de-reformation' is taking place in the United States too. Diana Butler Bass draws upon the language of The Great Awakening to speak of 'a new spiritual awakening' affecting the religious landscape of the USA. She contends that, following an evangelical revival during the 1970s, the USA is now 'caught up 
in the throes of a spiritual awakening, a period of sustained religious and political transformation during which our ways of seeing the world, understanding ourselves, and expressing faith are being, to borrow a phrase, "born again"” (Butler Bass 5 cf Roberts 11). In her analysis, this transformation extends beyond Christianity and other faiths into wider western culture, a claim echoed in the work of other scholars and cultural observers (Taylor 100).

All this being so, there has for some time been a need to explore in more detail amongst actual participants (be that in religion, or its allied activities) the many different ways in which religious alternatives take shape in Western culture. At a time when religion and spirituality are often sharply distinguished, the ways in which cultural practices contribute implicitly or explicitly to emerging forms of spirituality merit consideration. Woodhead, Heelas, Seel and Szerszynski (Spiritual Revolution), Clark (Angels to Aliens), Lynch Between Sacred and Profane, The New Spirituality) and Heelas (Spiritualities of Life) are examples of initial enquiries in this field. Sociological accounts of such developments are important, inter-disciplinary investigations still more so. Whilst religion scholars and theologians will look for what is 'religion-like', and explicitly or implicitly theological, sociologists rightly press for caution, asking whether participants themselves see their practices in religious terms. Conversely, whilst sociologists and social psychologists note and research religion-like practices, and offer accounts and explanations, scholars of religion and theology urge that their relatedness to religion, and the explanatory power of religious and theological frameworks, should not be overlooked.

Our purpose in this article is to explore one such channel of alternative spirituality. Amongst the many resources used in the West today for coping with, and structuring, everyday life the arts are clearly an alternative to religion for many, even feeding directly creatively into religious practice (Wuthnow). Within the arts, use of music is a common and vital resource (Sylvan; Lynch The role of popular music; Marsh and Roberts Soundtracks). It was doubtless always thus: people have long sung songs and drawn (and looked at) pictures as an accompaniment - and in part to interpret - 
human life (Bellah 24-7, Levitin). Robert N. Bellah sees rhythm as the foundation for human sociality, since it is the basis of group rituals that can mimetically define group identity and the roles of individuals within the group' (ibid 127). Furthermore, ours is the only genus with the capacity for keeping together in time (ibid 127-8). Thus rhythm, embodied mimetic action together with the evolution together of music and language ('musilanguage') provided the basis for ritualised behaviour and an emerging human sociality. As McGilchrist maintains, music 'has a vital way of binding people together, helping them to be aware of shared humanity, shared feelings and experiences, and actively drawing them together' (McGilchrist 105).

Relatively new is the explicit detachment of the making and appreciation of art and music from identifiably religious belief and practice. From the closing decades of the $20^{\text {th }}$ century onwards, in the West, it seemed right to celebrate the detachment and enjoy the new-found autonomy from religion (especially Christianity). A decade into the $21^{\text {st }}$ century matters look distinctly different. Religion has not gone away - explicitly or implicitly - and is even resurgent in some of its forms, even if also re-defined in more individualistic ways as 'spirituality.' If we are not quite yet at the point, academically and socio-politically, of welcoming back the closest possible alliance between arts, media and religious meaning-making, then there is at least a greater apparent willingness to acknowledge both the de facto functions of arts and media, and the fact that religion may not be redundant. If 'religion' is not always an acceptable phenomenon in the secular West, then the way music use and other artistic and cultural practices prove spiritually acceptable at least keeps religiosity as a human practice firmly in view.

At the beginning of his recent magnum opus on the place of religion within human evolution, Bellah (drawing upon Durkheim) defines religion as: 'a system of beliefs and practices relative to the sacred that unite those who adhere to them in a moral community' (Bellah 1). This configuration of definitions means, then, that we are looking, with respect to music and its uses, for beliefs and practices (what do people think/assume and do?), a sense of the sacred (what 
matters, in a way that people have somehow not decided for themselves, and which may be difficult to explain?), and some sense of community (whether virtual or real).

We are not suggesting that religious traditions are once more claiming back and seizing control of the arts. We also note that the recognition of greater friendliness between arts, media and religion may be more evident in the media itself than the academy, even whilst both spheres of activity and influence operate in avowedly secular societies across the West (if differently secular, depending on which part of the West is being talked about). Outside of departments actually studying religion, the academic world has arguably been slower to acknowledge the shift towards appreciation of the religion-like quality of much consumption of the arts.

Nevertheless, the task of gathering data about, analysing and drawing conclusions from evidence of what consumers of media and the arts are actually doing remains pressing. To undertake the task in a manner which facilitates multi-disciplinary scrutiny, does not load the dice in favour of one discipline over another and gives arts- and culture-users a chance to 'have their say' is notoriously difficult. In this paper we offer the first instalment of one such attempt. Deriving from analysis of data gathered from 231 music fans in the US and the UK in late 2009 and early 2010, the article offers the main findings of the quantitative data collected. Our aim was to gain a clear picture of how music-listening fits into people's life choices, and in particular their wider consumption of the arts and popular culture. We were especially interested in any notable differences, or unexpected similarities, between those self-identifying as religious and those not. We also ventured some more open questions, responses to which were often surprisingly full. Judging by the scale of many of the responses offered to the open questions, music fans were clearly happy to be asked, and wanted us to know how important music is for them, and how they use it. We shall draw out the findings of that qualitative data in a companion article. Our 231 respondents came from two main sources: a convenience sample of 103 from three locations, and 128 self-selected participants who offered responses in hard copy or electronically through a general appeal. The convenience sample comprised: 36 users of a denominational 
education and retreat centre in the SW United States, 29 based around an English Anglican parish in the Midlands, and 38 students from a Liberal Arts College in the Mid-West of the US. Only in the final of those three component groups of the convenience sample might it be said of some respondents that, although users of music, they were not music enthusiasts (i.e. they may not have responded to the questionnaire without peer pressure to do so). The 128 self-selected respondents replied to an on-line appeal, located on a University web-site, though may equally have received news of the survey by electronic means or by word of mouth from many who had themselves completed the questionnaire. It was also posted on a volunteer site of a major world development charity. Thus, whilst the resulting 231 responses cannot be said to be representative of appropriate proportions (per head of population) of religious members of either country providing participants (and 18 respondents were from outside the UK and the US), the range of religious respondents was not pre-selected across the whole group, nor did we control the number of self-identifying religious or non-religious participants. We should also acknowledge that all of our respondents must be considered affluent. As most can easily access the Internet and have resources to expend on concert-going or CDs/downloads, we are accessing the cultural practices of a relatively limited example of Western citizen.

Of the 231 respondents, 119 called themselves religious, 112 did not. Of the convenience sample of 103, out of which we had hoped to secure a number of religious respondents, 75 selfidentified as religious, 28 not. Of the 128 self-selecting respondents, 44 were religious (34\%), 84 not $(66 \%)$. Immediately, then it is clear that music fans who profess no religious affiliation, when given a chance, are enthusiastic in talking about their commitment to music. The scale, intensity and sheer enthusiastic openness of many respondents in the self-selecting group - which will be drawn on more in our later article - was striking.

Accepting the fact that two sub-groups of our convenience sample would contain (in the group based around and English parish) older respondents whose interests were more likely to be in classical or choral music than popular music - the main focus of our attention - and (in the 
student group based in the Mid-West US Liberal Arts College) younger respondents whose responses might be more immediate and more directly peer-influenced, we were able to sift out a core group of 21-60 year-olds (157 respondents, $68 \%$ of our sample) to prevent outliers skewing our evidence. Of these 157, 73 were male, 79 female, with 5 not providing information about gender; 79 self-identified as religious, 69 as non-religious, or (in 9 cases) chose not to answer. In our analysis of the data, we have opted to include those who did not reply with the non-religious group.

Whilst we neglect neither the classical and choral interests evident across our whole sample nor the more fashion-led responses of younger respondents, we were conscious that our central questions (What are people doing with popular music today? Are there are notable differences between the use of those identifying as religious and non-religious?) were more likely to be addressed directly within our core group of 157. In our presentation and analysis of the quantitative data in Section II we therefore drawboth on the full sample of 231 (135 UK, 78 US, 18 other) and the core group of 157 (98 UK, 50 US, 9 other) at different points. In addition, in Section III, we make use of distinctions between our convenience sample (103) and the self-selected group (128), given that the former provided us with a higher proportion of religious respondents $(75 / 73 \%)$ and latter a preponderance of non-religious listeners $(84 / 66 \%)$

II: Main Findings

\section{Types of music listened to}

In both the full sample and the core group, of an offered list of 16 types of music, rock and pop proved to be the most common forms of music listened to $(162 / 70 \%$ and $143 / 62 \%$, and $122 / 78 \%$ and $104 / 66 \%$ respectively). It is not surprising to find an increase in the percentages for the core group, despite the removal of some younger respondents from the full sample, due to the removal also of older classical and choral music listeners. Nevertheless, classical 
instrumental still features in both groups as the third most commonly listened-to music (124/54\% and 82/52\%). A distinction between religious and non-religious respondents does, however, appear when the detail of the core group is examined. As the third most popular form of music listened to, classical instrumental music is of considerably higher interest (47 out of $79 / 59 \%$ ) to religious listeners than the non-religious respondents amongst the core group (35 out of $78 / 45 \%)$. For the latter, indie (44/56\%) and folk $(36 / 46 \%)$ scored more highly. One surprising feature of the data was the higher proportion of religious respondents within the core group of 157 who listed hip-hop (30 over against 23).

Within the core group, then, non-religious respondents are slightly more likely than religious respondents to listen to rock, folk and pop, though are considerably more likely to listen to indie music. By contrast, religious respondents are more likely to listen to classical instrumental, country music (by some margin), jazz, hip-hop and rap.

\section{Themes within music listened to}

Respondents were offered nine possible prominent themes in the songs or music to which they listen: war \& peace, poverty, justice, religion, sexuality, family, love, spirituality, politics - with the possibility of adding any others in response to an open question. 'Love' was most prominent in both full and core samples $(161 / 70 \%$ and $106 / 68 \%)$. It was chosen as a prominent theme by a slightly higher percentage of religious respondents in each group $73 \%$ over against $66 \%$ in the full group; $69 \%$ over against $65 \%$ in the core group). The distinction is small, though may indicate either a more rosy or optimistic view of life on the part of religious listeners, or perhaps greater familiarity - through acts of worship - with singing about the theme in public.

A marginally greater percentage of the core group (46\% over $44 \%)$ listed sexuality as a prominent theme. Not surprisingly, religion and spirituality did not feature heavily as themes for those in either the full sample or core group who self-identified as non-religious $(15 \%$ and $18 \%$ respectively), though perhaps the surprise is that it featured at all. One striking difference 
between religious and non-religious respondents was, however, the stance taken towards 'justice' and 'politics' as themes. In each case, religious respondents revealed themselves to be more comfortable with the theme of justice than politics, whilst for non-religious respondents, the situation was reversed. Of the core group, $44 \%$ of religious respondents indicated that themes of justice were prominent in music they listened to, whilst this applied to only $31 \%$ of non-religious respondents. $45 \%$ of non-religious respondents in the core group offered 'politics' as a prominent theme, compared with only $28 \%$ of religious respondents. We shall want to suggest possible reasons for this later.

\section{Means of accessing music}

One of the most significant developments in patterns of music-listening in recent years has been the shift from use of hard storage of music (e.g. on CDs) to the collection of music in electronic forms (e.g. on an MP3 player or a lap-top computer). This has in turn led to different patterns of listening. Well beyond the Sony Walkman revolution of the 1980s, in which the number of cassette tapes which could be carried to enable a person to be 'wired for sound' was a major factor in limiting what could be listened to, the iPod generation can now carry tens of thousands of songs, either controlling their listening through choice, or subjecting themselves to the randomness of the shuffle facility, even if the 'canon' of material may be chosen in general terms by the iPod owner (Marsh and Roberts Personal Jesus 109-20).

Admittedly, things are moving very swiftly indeed as patterns of access to music change, but at the point of our survey, across the range of ages questioned, CDs remained the preferred means of listening. This applied both to the full and the core groups. $76 \%$ of the full sample use CDs, only $65 \%$ an MP3 player. Within the core group, the percentage of MP3 player-users, not surprisingly, increased (to $73 \%$ ). With the exception only of those aged 20 or under (where MP3 use was greater than CD use), CDs were still the preferred means of accessing music (79\%). 
There were no significant differences between religious and non-religious listeners either in CD use, or amongst MP3 use with the youngest respondents.

One slight difference is detectable in the accessing of music via radio. In both the full sample and core group there was evidence of religious listeners making slightly more use of the radio in comparison with using a lap-top to access music.

\section{Frequency of listening}

Most of the respondents listen to music daily ( $83 \%$ of the full sample, $80 \%$ of the core group).

The slight reduction of percentage in the core group is explained by the removal of the youngest members in the survey, for whom music access is a daily habit for nearly all (34 out of the 35 respondents aged 20 or under). In both groups, however, there is a slight increase in the number of non-religious listeners who access music daily ( $83 \%$ over against $77 \%$ of religious respondents in the core group; $86 \%$ over $81 \%$ in the full sample). It would be inappropriate to draw a major causal conclusion from this data according to which the less religious one is, the more one is likely to listen to music and/or use music in a religion-like way. But the correlation is nevertheless clear: music fans of all types take their music very seriously (as a daily habit, for most), and those who do not also inhabit religious practices listen even more in comparison with listeners who self-identify as religious.

\section{Listening in the context of other activities}

How, though, do these listening habits fit within a broader framework of cultural and media activity? In addition to asking participants about whether they were members of a political party - already considered above - we asked questions of participants about their reading and filmwatching habits. The data collected shows that religious listeners are more likely than their nonreligious counterparts to be readers of non-fiction ( $61 \%$ in the full sample, compared with $52 \%$; $56 \%$ compared with 51\% in the core group). Conversely, non-religious listeners read more 
novels $(70 \%$ compared to $66 \%$ in the full sample; $76 \%$ to $63 \%$ in the core group of $21-60$ yearolds), more newspapers and magazines (71\% over against $63 \%$ in the full sample; $73 \%$ compared with $57 \%$ in the core group) and are more likely to consult music fan-sites, both official and unofficial, to support them in their listening habits - although it must be noted that consultation of fan-sites as a whole was surprisingly low across all those questioned ( $25 \%$ of the full sample of 231 consulting official sites, and 19\% unofficial).

Unsurprisingly, religious listeners are more likely both to have consulted (at any time) and be active users of religious scriptures. The Christian Bible and the Buddhist scriptures were the most used $(81 \%$ of the full sample had read the Bible at some point, $17 \%$ the Buddhist scriptures). One point - indeed, the only point - at which non-religious listeners made greater use of a religious text was amongst the core group of 21-60 year-olds where more non-religious listeners had referred to the Bhagavad Gita than the religious listeners (18\% over $16 \%)$. With regard to film-watching, when offered a range of film genres, the respondents overwhelmingly chose comedy as their most-watched type of film $(65 \%$ of the full sample, $63 \%$ of the core group). Drama, action and adventure then featured most prominently (in that order), religious listeners indicating a much clearer preference for drama, and, indeed, providing a much greater indication of film-going as a practice than non-religious listeners. Only one of genres offered (comedy) attracts more than half of the non-religious listeners on a regular basis (64\%). All other kinds of film score lower than 50\%. By contrast, comedy, drama and action all exceed $50 \%$ for religious listeners in both the full sample and the core group.

Within the responses, one statistic was, however, quite striking. For non-religious listeners in the core group of 21-60 year-olds, science fiction films appeared above action, adventure and romantic comedies. This may, of course, be due to the fact that we just happened to have stumbled upon a group of SciFi enthusiasts, though there was no evidence of any such grouping of respondents. When taken alongside other evidence from this section, it is, however, possible 
to posit tentative conclusions about patterns of consumption of the arts, media and popular culture, and how music fits into this. We shall venture some such conclusions in section III.

\section{Male and female responses}

Across the many queries asked of the data available to us, we noted no significant differences between male and female respondents. Our samples produced roughly a 50\% split (with marginally more female respondents). Of the 217 who indicated their gender from the full sample of 231, marginally more (and thus a proportionately higher percentage of) males selfidentified as religious (58 out of $103 / 56 \%$, compared with 56 out of 114 females/49\%). These differences became negligible in the core group of 157 21-60 year olds, of which 73 were male (39 of them religious) and 79 female (38 religious).

More drilling down into the data would, of course, be possible (do more men or women like comedy films? are the types of music enjoyed evenly spread?), but it is not immediately germane to our current task to explore potential patterns of music use by religious and non-religious listeners.

\section{III: Music Use as a Religious Habit? - Analytical Observations}

In the light of the data summarized above, can anything be concluded about how ordinary music-listeners are using music in the contemporary West? More particularly, can anything be concluded about how music use relates to, imitates or replaces religious practice? It must first be acknowledged that despite the considerable data produced, and the density of the qualitative material yet to be fully analysed, no simple conclusions can be drawn. There is, for example, no clear evidence to support a view that those who self-identify as religious people listen to music only or primarily for religious ends, or that their religiosity creates a major difference in the way in which they listen, or any benefits they accrue from the listening. It is not possible to pinpoint 
from the statistical data clear divisions between religious and non-religious listeners with respect to how listeners behave. The differences noted, which we shall go on to explore, may appear relatively slight though do prove significant. Even more significant differences will become evident in the qualitative material which music fans have provided, to be explored in a later article (e.g. their use of language about the kinds of emotional experiences they enjoy when listening, their reasons for choosing particular pieces of music as especially significant, their stated understanding of the place of music in their coping with/structuring of life). From our statistical data nevertheless, three insights can be presented. First, it is clear from our presentation of the data about how listeners assess the political content or function of music that there is a difference in religious and non-religious listeners' approaches. Religious music-users may relate more readily to 'justice' as a theme in the music to which they listen because of the terms in which political matters are handled within their faith traditions, whilst not considering the music they listen to explicitly political. Furthermore, they may be either less political, or deem that their political interests are explored and expressed more directly through their religious beliefs and practice. Here, the latter is the more feasible than the former, as both in the full sample, and especially in the core group, religious listeners are much more likely than nonreligious to be active supporters of a political party ( $52 \%$ of religious listeners in the full sample, compared with $23 \% ; 52 \%$ also in the core group, compared with $22 \%$ of non-religious listeners). Perhaps music is more clearly a different kind of outlet for self-expression or reflection. Nonreligious listeners, by contrast, may actively seek out political music because it is more directly a channel for the articulation of their values, where they may be no other immediate communal context (real or virtual) through which their commitments are explored and expressed. This is especially the case given that non-religious listeners are less likely to be members of a political group. We may see here that in an age when it is less likely that people join groups of any kind (Putnam) it is still true that religious people are more likely to sign up not just to their faith communities, but other groups too. 
From the evidence of the greater participation by religious listeners in the structures of politics (a higher proportion of members of a political party) it is clear, then, that for them music needs to carry no specific political role, nor serve a political need. Political interests are either served in the context of active political commitment, or through explicit religious activity (or both together). By contrast, non-religious listeners with a political interest, whether or not this is linked to active, explicit political engagement, are more likely to want to see this interest reflected in their musical interests. As a result, religious listeners may appear 'less political' in their musical tastes, and this is reflected, we suggest, in the distinction between religious listeners' interest in songs of justice, and non-religious listeners' more explicit appeal to politics as a theme.

It would be too speculative to extend reflection on this observation much further. In keeping, however, with our proposal that music creates an affective space within and around which cognitive work is also undertaken by listeners (Marsh and Roberts Personal Jesus 16-21), then for non-religious people music can function as one of the social settings where political values are worked out and explored. Where people do not have an obvious (religious, or religion-like) group to relate to, then a communal setting is found in and through which political commitments are espoused. Bands and artists create followings (real [in concert] and virtual) amongst which political and ethical reflection occurs. Virtual communities of music-fans can thus become political communities by virtue of individuals' use of music for political stimulus. This reflection leads onto a second insight: consideration of what communal world, schema or cognitive framework 'work' of listening may be taking place. By this we mean how much attention is in practice given to the often inchoate or unacknowledged worldview or thoughtworld within which a listener listens. Music can provide tags or triggers to the thought-worlds within which people live. But how conscious are listeners of the narratives or metaphors they live by (Lakoff and Johnson, McAdams)? Religious people might, of course, be very conscious (and more aware than non-religious listeners) of the community, schema or framework within which they listen. This may, for example, for many of our respondents be quite explicitly 'faith 
community, faith/belief, theology', even quite explicitly 'church and faith.' But this cannot be assumed. Many religious adherents may take for granted the structure of belief within which they live, move and have their being, though may not be fully aware of how it shapes them. By contrast, non-religious listeners may be very clear about the philosophical or political framework within which they listen, having more clearly chosen their value-system.

Be that as it may, the data supplied by respondents about the broader cultural context, and collection of habits and practices, within which their listening occurs, provide a reminder that life-shaping practices take place within a narrative framework. Indeed, as Paul Ricoeur has noted, narrative 'proves to be the first laboratory of moral judgement' (Ricoeur 140). It is telling that non-religious listeners show greater interest in novels over non-fiction in their reading habits. It is also significant that science fiction as a genre surfaces as of greater interest to non-religious listeners in film-going habits. Science fiction fans are known to be especially devoted to specific series (TV, films, video games or books) as they interweave reflection with their enjoyment of the genre (Porter, Cowan). Whether such activities always constitute conscious meaning-making akin to religious behaviour may be a conclusion too far. But the differences which are evident between religious and non-religious music-users do indicate that alongside the practice of listening, where there is no explicit religious narrative world, other resources are found and used. Given the evident higher use of music fan-sites by non-religious listeners, this does suggest a different kind of engagement with the music itself (or the lyrics, or the life/lives of performers) as part of the resourcing process. For all that music-users may share together (e.g. a conviction that love is a central theme in music, and an intensity of often daily engagement with music), these differences are significant.

Relevant here also is the changing role of soundtracks to TV programmes and video games. For much of the past they have been deemed 'incidental' music designed to set the mood for particular scenes. Although the music used in TV shows and video games continues to do that, the tracks that are used are often drawn from the world of popular music and can be a major 
source of new musical experiences for viewers. Not only is this music placed within a narrative framework in the programme or game, it can then be taken up and placed within further narrative streams in discussion of the show or game in various forms social media (Johnson). Theme tunes act as triggers; 'closing songs' may provide neat (and false, or premature) closure to TV or film plots. Yet the affective and cognitive 'work' being undertaken, consciously and unconsciously, in the processing of the listening experiences lure people into the narrative worlds which they inhabit both to enjoy the artistic/cultural event of listening (and perhaps watching too) and to 'think through', however, inchoately, the values within and the structures of the stories in and through which they live.

A third insight from the data examined connects the technological shifts now at work in the practice of listening, with the regularity with which the listening occurs. Here, the significant difference between religious and non-religious listeners in our self-selected sample (of 128 respondents) becomes especially important. 72 of the 84 non-religious respondents from the self-selected sample $(86 \%)$ listen to music daily. This is considerably higher than the religious listeners in the same group ( 28 out of $44 / 64 \%$ ). This means that of those music fans who took the trouble to contact us and enthuse about their listening habits, it was the non-religious participants who made a specific point about the intensity of their listening. If we are therefore able to speak of a 'serious listener' (as opposed to an occasional, incidental listeners), then we see here amongst our respondents an indication that a greater intensity of 'devoted' listening occurs amongst the nonreligious respondents.

Furthermore, whilst CD remains the format in which most people in our survey (religious and not) access their music a greater proportion of the non-religious listeners in this sample listen to music on an MP3 player (73\% as opposed to 70\%). And together, this group of MP3 users $(72 \%)$ almost matches the core group of listeners $(73 \%)$. The self-selected enthusiasts and the core group of 21-60 year olds thus offer evidence that nearly three-quarters of committed musicusers are now daily listeners on MP3 players. Music-listening is for some a daily habit, perhaps 
even a daily 'spiritual' discipline. Examination of the qualitative evidence provided by our respondents will reveal whether this is any more than time-filling, or making a journey to work more bearable. It will be vital to investigate whether users themselves deem such heavy use as entertainment or relaxation (or both and more). But the scale and intensity of the habit are clear.

\section{IV: Concluding Reflection}

Is this 'religion'? Without further input from the qualitative data, it can be called so only in the very limited sense that it is a regular, binding commitment. Using Robert Bellah's as a working definition, we would go too far to say that contemporary listeners to music gather (even virtually) around 'a system of beliefs and practices relative to the sacred that unite those who adhere to them in a moral community.' Ethnomusicologists would in any case (quite rightly) want to draw attention to the diversity and cultural complexity of different forms of music. Claims for universality in music are difficult to make. What can be said, however, is that substantial numbers of people want to listen to music in an intense, regular way, are clearly happy to talk about this habit, and reveal through the correlations between their listening and other lifechoices how it fits into their everyday practice and life-structuring. To define the habitual practice as 'religion', 'spirituality' or even a form of 'piety' would be much too neat. 'Religion' is probably too socially structured for what we have found so far, 'Spirituality' is too vague, or may imply too close a focus on the inner life of the listener. That there are at least emotional dimensions to the practice of listening is clear. Whether these should be called 'spiritual' (and what that means) needs further scrutiny. 'Piety' is not what we are identifying, although the moral, disciplined approach implied in piety, whilst not directly reflected in music-listening, is at least echoed in the regularity and intensity of listening. In formal terms at least, intense listeners might be said to be devoted practitioners. 
What such a habit may do to and for such listeners, whether it is clearly a 'meaning-' or 'sensemaking' practice and whether radically different things happen for those self-identifying as religious in comparison with those who do not, awaits further input from the qualitative findings of our research. In our later article we shall want to press the evidence for whether 'moral communities' do form, even if in informal ways, around the artists being listened to, and amongst the friends who share in musical experiences. And we shall want to ask how beliefs and values take more concrete shape for listeners - either as individuals or in communal settings - in relation to the music heard. We shall then be in a better position to assess the form and content of the 'sonic practices' we are exploring.

Clive Marsh is Director of the Vaughan Centre for Lifelong Learning, University of Leicester. Vaughan S. Roberts is Vicar of the Collegiate Church of St Mary and Team Rector of Warwick. The authors' latest co-written book is: Personal Jesus: How Popular Music Shapes Our Souls (Grand Rapids: Baker Academic 2012). CORRESPONDENCE: Dr. Clive Marsh, Vaughan Centre for Lifelong Learning, University of Leicester, UK; Revd. Dr. Vaughan S Roberts, Collegiate Church of St Mary, Warwick, UK.

\section{REFERENCES}

Bellah, Robert N. Religion in Human Evolution: from the Paleolithic to the Axial Age. Cambridge, MA \& London: The Belknap Press, 2011

Butler Bass, Diana. Christianity After Religion: The end of church and the birth of a new spiritual awakening. New York: HarperOne, 2012

Clark, Lynn Schofield. From Angels to Aliens: Teenagers, the Media, and the Supernatural. New York: Oxford University Press, 2003. 
Cowan, Douglas. Sacred Space: The Quest for Transcendence in Science Fiction Film and Television. Waco, TX: Baylor University Press 2010.

Davie, Grace. Religion in Modern Europe: A Memory Mutates. Oxford \& New York: Oxford University Press, 2000.

Johnson, Steven. Everything Bad is Good for You: How Popular Culture is Making Us Smarter. London: Allen Lane 2005.

Lakoff, George and Mark Johnson. Metaphors We Live By. Chicago and London: University of Chicago Press, 1980.

Lyden, John. Film as Religion: Myths, Morals, Rituals. New York: New York University Press, 2003. Lynch, Gordon. "The role of popular music in the construction of alternative spiritual identities and ideologies." Journal for the Scientific Study of Religion 45.4 (2006): 481-8.

---. "Public media and the sacred: a critical perspective." Eds. Gordon Lynch, Jolyon Mitchell and Anna Strhan. Religion, Media and Culture: A Reader. London: Routledge 2012. 244-50.

McAdams, Dan. P. The Redemptive Self: Stories Americans Live By. New York: Oxford University Press USA, 2006.

McGilchrist, Iain. The Master and his Emissary: The Divided Brain and the Making of the Western World. New Haven \& London: Yale University Press, 2010.

Marsh, Clive and Vaughan S. Roberts. 'Soundtracks of Acrobatic Selves: Fan-Site Religion in the Reception and Use of the Music of U2', Journal of Contemporary Religion 26 (2011): 419-432. Marsh, Clive and Vaughan S. Roberts. Personal Jesus: How Popular Music Shapes Our Souls. Grand Rapids: Baker Academic 2012.

Percy, Martyn. The Ecclesial Canopy: Faith, Hope, Charity. Farnham \& Burlington: Ashgate Publishing, 2012

Porter, Jennifer E. Star Trek and Sacred Ground: Explorations of Star Trek, Religion and American Culture. New York: State University of New York Press, 1999. 
Putnam, Robert D. Bowling Alone: The Collapse and Revival of American Community. New York: Simon and Schuster 2001.

Ricoeur, Paul. Oneself as Another. Chicago \& London: Chicago University Press, 1992.

Roberts, Vaughan S. 'US and UK converge on "nones" Church Times 2 $2^{\text {nd }}$ August 2013: 11

Sylvan, Robin. Traces of the Spirit: The Religious Dimensions of Popular Music. New York: New York University Press 2002.

Taylor, Barry. Entertainment Theology: New Edge Spirituality in a Digital Democracy. Grand Rapids: Baker Academic, 2008.

Woodhead, Linda. "Mind, body and spirit: it's the de-reformation of religion" The Guardian, May $7^{\text {th }} 2012$, http://www.guardian.co.uk/commentisfree/belief/2012/may/07/mind-body-spiritdereformation-religion (accessed July 10th 2012).

Woodhead, Linda. "British religion has changed dramatically and the implications for policy and practice are far reaching.” http://www.ahrc.ac.uk/News-and-Events/News/Pages/Britishreligion-has-changed-dramatically-and-the-implications-for-policy-and-practice-are-far-reach.aspx (accessed June 5th 2012) 